\title{
CLINICAL AND LABORATORY FINDINGS OF DISSEMINATED Mycobacterium avium COMPLEX INFECTION (DMAC) IN A PAIR MATCHED CASE-CONTROL STUDY
}

\begin{abstract}
SUMMARY
A pair matched case/control study was conducted from January 1991 to 30 June 1992 in order to define clinical and laboratory findings associated with DMAC infection in AIDS patients. Since DMAC infection is usually associated with advanced immunodeficiency, and therefore also with other opportunistic illnesses, in addition to the number of CD4 ${ }^{+}$lymphocytes, cases and controls were matched using the following criteria: date of AIDS diagnosis and antiretroviral therapy, number and severity of associated opportunistic infections and, whenever possible, type of Pneumocystis carinii prophylaxis, age and gender, in this order of relevance. Cases (defined as patients presenting at least one positive culture for MAC at a normally sterile site) and controls presented CD4+ lymphocyte counts below $50 \mathrm{cel} / \mathrm{mm} 3$. A significantly higher prevalence of general, digestive and respiratory signs, increased LDH levels, low hemoglobin levels and $\mathrm{CD}^{+}$cell counts were recorded for cases when compared to controls. Increases in $\gamma \mathrm{GT}$ and alkaline phosphatase levels seen in cases were also recorded for controls. In conclusion, the strategy we used for selecting controls allowed us to detect laboratory findings associated to DMAC infection not found in other advanced immunosuppressed AIDS patients without DMAC.
\end{abstract}

KEYWORDS: DMAC; AIDS; Clinical signs; Laboratory signs.

\section{INTRODUCTION}

AIDS is characterized by multiple opportunistic diseases that can affect an immunosuppressed HIV-infected patient concomitantly or at different moments. The incidence of disseminated disease due to Mycobacterium avium complex (MAC) has risen dramatically since AIDS epidemic appeared and has become the most common opportunistic infection of bacterial origin among AIDS patients in the United States 2,6,12 until a powerful treatment for HIV disease became current in developed countries ${ }^{17}$.

Much of the information available about DMAC infection has been obtained from AIDS patients with long term HIV infection and advanced immunodeficiency since the risk of developing DMAC increases as the $\mathrm{CD}^{+}$lymphocyte count declines below $100 / \mathrm{mm} 3^{2}$. In these cases, an overlap of signs and symptoms with those of other HIV-associated diseases processes is expected to occur. In addition, patients with comparable $\mathrm{CD}^{+}{ }^{+}$cell counts can present different prognosis as the result of clinical status, differences in quantity and quality of prophylactic and therapeutic regimens usually used "for life" and viral load, the greatest predictor of survival nowadays ${ }^{7}$. For these reasons, and because viral load was not available before 1996, we figured that patients could be more comparable if we consider date of AIDS diagnosis, date of antiretroviral therapy and the cumulative number and severity of opportunistic diseases instead of counting the isolate number of CD4 ${ }^{+}$ lymphocytes.

The objective of this paper is to describe clinical and laboratory findings associated with DMAC infection in AIDS patients. The strategy of matching cases and controls using clinical parameters and a CD4 threshold rather than an isolate CD4 counts objectified the selection of individuals clinically and immunologically comparable to cases. Studying these two comparable groups we will try to identify those findings usually reported to DMAC infection that could be the result of concurrent immunosuppression.

\section{METHODS}

A pair matched case/control study was carried out. All HIVinfected patients seen at the Infectious Disease Department of the Rothschild Hospital (Paris-France), and presenting at least one positive specimen culture for MAC at a normally sterile site, (from January 1st 1991 to 30 June 1992) were considered eligible cases. We selected control AIDS patients based on the following criteria of exclusion: MAC diagnosis or empirical treatment for tuberculosis (MAC prophylaxis was not available at this time in our center), number of $\mathrm{CD} 4^{+}$cells above 50

(1) Service de Maladies Infectieuses et Tropicales - Hôpital Rothschild, Paris, France

(2) NESC - Federal University of Rio de Janeiro, RJ, Brasil

(3) Department of Immunology, Instituto Oswaldo Cruz, FIOCRUZ, Rio de Janeiro, Brazil.

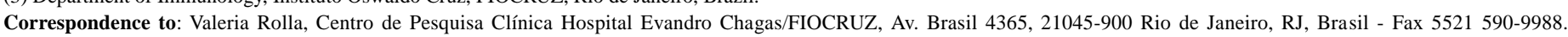
Email: valeria@fiocruz.br 


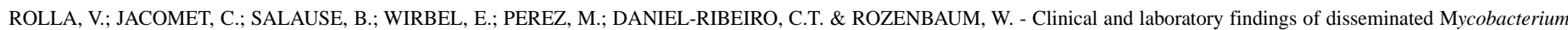
avium complex infection (DMAC) in a pair matched case-control study. Rev. Inst. Med. trop. S. Paulo, 41 (5): 273-277, 1999.

cell/mm3 at the moment of DMAC diagnosis of the corresponding index case (this threshold was defined after an evaluation of $\mathrm{CD}^{+}$counts for cases). Controls that presented clinical and laboratory signs suggestive of DMAC infection (prolonged unexplained fever and anemia) were excluded. Cases and controls were matched by date of AIDS diagnosis, date of antiretroviral therapy, number and severity of opportunistic diseases and, whenever possible, by Pneumocystis carinii Pneumonia (PCP) prophylaxis, age and gender (in this order of relevance). The bestmatched control was selected.

Clinical charts and laboratory records were reviewed retrospectively. A computerized database provided almost all information needed for this study. Clinical signs and symptoms described at the database were the result of the regular consultations (only bacteriological information was obtained directly from the laboratory). Demographic data were analyzed and included age, gender and risk group. Clinical information was divided as follows: Karnofsky performance score (at time of first clinical signs and at the moment of DMAC diagnosis as defined by the first positive MAC culture), general (fever, night-sweats, weight loss), pulmonary (cough, dyspnea) and digestive (diarrhea, abdominal pain, nausea) signs and symptoms as well as enlargement of liver, lymph nodes or spleen. Weight loss was defined as a loss of more than $10 \%$ of weight during the preceding 6 months and diarrhea as three or more loose stools per day. Liver and lymph node enlargement was detected by ultrasonography in cases where biological signs of hepatic injury were present. AIDS was defined according to the 1987 definition of the Centers for Disease Control and Prevention ${ }^{3}$.

Laboratory data were analyzed at the time of the first positive culture and included hematological parameters (white blood cell count and hemoglobin levels), liver function tests (ALT, AST, alkaline phosphatase, LDH and $\gamma$ GT levels). We tolerated a gap of 2 months for results concerning $\mathrm{CD} 4^{+}$cell subset count 32 microglobulin and p24 antigenemia.

Table 1

Weight and Karnofsky score recorded before AIDS, and at different times of DMAC infection

\begin{tabular}{lccc}
\hline & cases & controls & \\
\cline { 2 - 4 } & mean $( \pm$ SD) & mean $( \pm$ SD $)$ & $\mathrm{p}^{*}$ \\
\hline $\begin{array}{l}\text { reported normal } \\
\text { weight }(\mathrm{kg})\end{array}$ & $67( \pm 8)$ & $68( \pm 9)$ & 0.62 \\
& & & \\
at first signs: & & & \\
Karnofsky sc. & $91( \pm 8)$ & $94( \pm 11)$ & 0.06 \\
weight $(\mathrm{kg})$ & $62( \pm 8)$ & $66( \pm 10)$ & 0.02 \\
& & & \\
at diagnosis: & $75( \pm 20)$ & $92( \pm 12)$ & $<0.01$ \\
Karnofsky sc. & $57( \pm 8)$ & $65( \pm 10)$ & $<0.01$ \\
weight $(\mathrm{kg})$ & & & \\
\hline
\end{tabular}

*Matched $t$ test concerns results of comparison between case and control values made at each time considered; controls are AIDS patients without DMAC.
Culture of specimens: Blood samples $(10 \mathrm{ml})$ were obtained by a sterile technique, placed in a lysis-centrifugation blood culture tube (Isolator tubes - DuPont Instruments, Newtown, CT), and centrifuged at $3000 \mathrm{~g}$ for $30 \mathrm{~min}$. The supernatant was aseptically removed and discarded. The remaining concentrate was totally inoculated onto Lowenstein Jansen media (LJ) and Coletsos (Co). Samples from biopsies were also collected into Isolator tubes, before being seeded in $\mathrm{LJ}$ and $\mathrm{Co}$ media. All tubes were incubated at $37^{\circ} \mathrm{C}$ and examined once a week for as long as 3 months. The source, strain and number of colonies were recorded. A microscopic examination of smears stained with auramine was performed in all samples except blood. MAC was identified by using the Gen-Probe Rapid Diagnostic System (Gen-Probe, Inc., San Diego, Calif. $)^{22}$. The results were confirmed by standard biochemical methods.

Statistical analysis: Association between signs, symptoms and laboratory parameters of DMAC infection was assessed by the matched $\mathrm{T}$ test or Mc Nemmar test of symmetry whenever appropriate, using the SPSS package (Statistical Program for Social Science, Chicago, Illinois $)^{24}$.

\section{RESULTS}

Among the 308 AIDS cases followed at the Department of Infectious Diseases from January 1991 to June 1992, 52 (16.8\%) had the diagnosis of DMAC infection. In eleven (3.57\%), DMAC was the first AIDSdefining condition. DMAC infection occurred after a median of 15 (mean $20.39 \pm 17.39)$ months after AIDS diagnosis.

Both groups of AIDS patients (52 DMAC infection cases and 52 controls) consisted of 50 males and 2 females. The median age was 37 (mean $37.8 \pm 7.5$ ) for DMAC patients and 38 (mean $38.2 \pm 6.7$ ) for controls. AIDS was sexually transmitted in 49 cases of MAC infection and in 50 controls and appeared as result of blood transfusion in 3 cases and 2 controls, respectively.

DMAC was due to Mycobacterium avium in all cases. It was diagnosed by blood cultures in $49(94.2 \%)$ cases, in bone marrow aspirate in $2(3.8 \%)$ and from a liver biopsy in one case. Other cultures had been performed before in 31 of the 52 patients and, although positive in nine of them $(29.03 \%)$, M. avium was cultivated only from specimens obtained from a normally non-sterile site (respiratory tract). The mean time to cultivate and identify MAC was 31.3 days and $64 \%$ of patients presented less than 3 (mean $10 \pm 21$ ) colonies.

The mean time elapsed from the first clinical sign of MAC infection to its diagnosis was $119.4 \pm 105$ days (median 95 days).

Mean and median values for Karnofsky score and weight are shown in Table 1. From the first MAC clinical signs to diagnosis a significant weight loss was recorded paralleling the deterioration of the general status as reflected by the progressive increase in the difference of weight and Karnofsky score between cases and controls.

Table 2 shows the clinical signs and symptoms observed at the time of DMAC diagnosis and in control AIDS patients. Increased frequencies for general, digestive and respiratory symptoms, but not for liver or lymph node enlargement, were observed among MAC patients. Table 3 also shows the laboratory findings at the time of DMAC diagnosis. Cases 

avium complex infection (DMAC) in a pair matched case-control study. Rev. Inst. Med. trop. S. Paulo, 41 (5): 273-277, 1999.

Table 2

Clinical signs and symptoms associated to DMAC infection

\begin{tabular}{lccccc}
\hline & \multicolumn{2}{c}{ Agreeing pairs } & \multicolumn{2}{c}{ Disagreeing pairs } & \\
\cline { 2 - 6 } $\begin{array}{l}\text { Signs \& } \\
\text { symptons }\end{array}$ & YES/YES & NO/NO & YES/NO & NO/YES & Prob. \\
\hline digestive & 14 & 7 & 27 & 4 & $<0.01$ \\
respiratory & 5 & 14 & 31 & 2 & $<0.01$ \\
general & 5 & 0 & 44 & 0 & $<0.01$ \\
hepatic \& & 10 & 19 & 15 & 8 & 0.14 \\
lymphatic & 10 & & & & \\
\hline
\end{tabular}

"Yes/Yes" for agreeing pairs means that both case and control presented the symptom. "Yes/No" means that only the case presented the symptom and "No/Yes" that only the control did.

Table 3

Hematological, biochemical and immunological parameters at the time of DMAC diagnosis

\begin{tabular}{lccc}
\hline \multicolumn{4}{c}{ Mean \pm SD } \\
\hline Case & Control & $\mathrm{p}$ \\
\hline WBC & $3166 \pm 1302$ & $2905 \pm 913$ & 0.22 \\
HEMOGLOBIN & $9.8 \pm 1.7$ & $12.3 \pm 1.8$ & $<0.01$ \\
PLATELETS & $191 \pm 95$ & $170 \pm 62$ & 0.25 \\
LDH & $456 \pm 154$ & $379 \pm 127$ & $<0.01$ \\
$\gamma$ GT & $102 \pm 153$ & $72 \pm 110$ & 0.25 \\
ALK. PHOSP. & $138 \pm 177$ & $130 \pm 221$ & 0.85 \\
ALT & $30 \pm 28$ & $31 \pm 17$ & 0.8 \\
AST & $33 \pm 22$ & $29 \pm 14$ & 0.22 \\
$\beta 2$ MICRO & $3.7 \pm 1.5$ & $3.1 \pm 1$ & 0.07 \\
p24 Ag & $126 \pm 383$ & $65 \pm 123$ & 0.21 \\
CD4 & $15 \pm 11$ & $21 \pm 14$ & 0.02 \\
\hline
\end{tabular}

WBC $=$ white blood cells (cell/mm3), hemoglobin $(\mathrm{g} / \mathrm{dL}) \mathrm{LDH}=$ lactate dehydrogenase $(\mathrm{U} / \mathrm{mL}), \gamma \mathrm{GT}=$ gamma glutamil transpeptidase $(\mathrm{U} / \mathrm{L})$, alk. phosp. $=$ alkaline phosphatase $(\mathrm{U} / \mathrm{L}), \beta 2$ micro $=\beta 2$ microglobulin $(\mathrm{mg} / \mathrm{dL}), \mathrm{p} 24 \mathrm{Ag}=\mathrm{p} 24$ antigen $(\mathrm{pg} / \mathrm{mL}), \mathrm{CD}^{+}=\mathrm{CD} 4^{+}$lymphocytes (cell/mm3).

Table 4

Association of clinical signs and symptoms with mean Lactate dehydrogenase levels (U/L) in AIDS patients according to the clinical signs and symptoms

\begin{tabular}{lccc}
\hline signs/symptoms & & LDH mean \pm S.D. & P \\
\hline PULMONARY & YES & $465 \pm 167$ & 0.52 \\
& NO & $432 \pm 150$ & \\
\hline DIGESTIVE & YES & $460 \pm 164$ & 0.71 \\
& NO & $440 \pm 119$ & \\
\hline DIGESTIVE + PULMONARY & YES & $435 \pm 149$ & 0.75 \\
& NO & $458 \pm 156$ & \\
\hline
\end{tabular}

presented high values for $\gamma \mathrm{GT}$ and alkaline phosphatase that, however, were not different from those recorded for controls. Significantly lower hemoglobin levels and CD4 ${ }^{+}$cell count values, and higher LDH levels were detected in cases as compared to controls. In our study, cases presented higher frequencies of respiratory signs than controls. However, high LDH values do not seem to be associated with pulmonary involvement since cases that presented pulmonary signs did not present higher LDH values. We have also tried to correlate this finding with the presence of digestive signs but even when both digestive and respiratory factors were considered together no correlation appeared (Table 4). A possible overlap of PCP and DMAC was also explored but this association could not be found.

The median p24 Ag value was $23 \mathrm{pg} / \mathrm{ml}$ for cases (mean $125.7 \pm$ 382.6) and 10 for controls (mean $65 \pm 122.6$ ). Among the agreeing pairs, 11 cases and respective controls had positive p24 $\mathrm{Ag}(+/+)$ and 9 pairs had negative values (-/-). Twelve cases were positive for p24 Ag when their respective control presented negative values $(+/-)$ and 11 cases were negative with a positive respective pair $(-/+)$ (Mc Nemar test of symmetry $=0.83$ and probability $=0.04$ )

\section{DISCUSSION}

The incidence of DMAC infection detected here (16.8\%) in AIDS patients is in agreement with the $16 \%$ value previously reported by HAVLIK et al. ${ }^{12}$ and the $18 \%$ value observed by CHIN et al. ${ }^{5}$ in patients with less than $50 \mathrm{CD}^{+}$cells/ $\mu 1$. In France, $12.5 \%$ of AIDS patients were treated for DMAC in $1991^{6}$. In Brazil DMAC infection was diagnosed in $16 \%$ of blood cultures of patients presenting unexplained fever who were selected for clinical suspicion of $\mathrm{DMAC}^{10}$ and in $18.4 \%$ of bone marrow specimens ${ }^{1}$. NIGHTINGALE et al..$^{23}$, however, studying patients presenting less than $100 \mathrm{CD}^{+}$cells, even without clinical signs and symptoms of DMAC infection, showed that sequential blood cultures could improve the sensitivity of detection of MAC bacteremia. Using this approach, these authors observed incidences of $21 \%$ and $43 \%$ after one and two year follow-up, respectively. This last figure is indeed closer to that $(47 \%)$ corresponding to the prevalence of histopathologic evidence of MAC infection at autopsy ${ }^{29}$. However, the adoption of prophylactic regimens for DMAC since 1993 and the availability of Protease Inhibitors (PI) as part of highly active antiretroviral treatment (HART) in 1996 have contributed to a significant drop in these values in some countries ${ }^{13,19,21,26}$. Recent reports showed even recovery of DMAC infection without specific treatment in patients using HART ${ }^{11}$.

The mean time elapsed between diagnosis of AIDS and diagnosis of DMAC infection was 20 months. HAVLIK et al. ${ }^{12}$ reported a 4.5 months median in patients seen from 1985 to 1988 and an increase to 8 months in patients studied between 1989 and 1990. In 1991, HORSBURGH et $a l .{ }^{15}$ reported a mean of 7 to 15 months. The use of antiretroviral and of PCP prophylaxis in all our patients may have prolonged survival increasing the risk of DMAC and of any other infections associated with advanced immunodeficiency.

The age, sex and route of transmission of HIV of our MAC cases reflect a trend also recorded for our AIDS patients as a whole. We did not find differences concerning age between cases and controls. Eventhough our finding may have been biased by the pairing criteria we used (even if age was considered as the last item of selection for controls) 


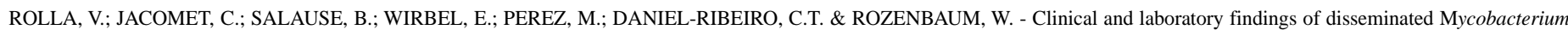
avium complex infection (DMAC) in a pair matched case-control study. Rev. Inst. Med. trop. S. Paulo, 41 (5): $273-277,1999$.

it seems to agree with data reported by LASSEUR et al. ${ }^{20}$ who were also unable to observe differences concerning these factors in a cohort of 100 French patients. HAVLIK et al. ${ }^{12}$ and HORSBURGH et al. ${ }^{15}$ however could show a significant relationship between young age and DMAC infection.

The predominant clinical presentation of DMAC in our patients was the already described syndrome including fever, night sweats and weight $\operatorname{loss}^{14,16}$, anemia and elevated serum levels of alkaline phosphatase ${ }^{12}$.

Anemia is a common manifestation in patients with human immunodeficiency virus infection ${ }^{25,28}$. The degree of anemia in patients with CDC-defined AIDS is usually mild with a mean hemoglobin level ranging from 9.0 to $11.0 \mathrm{~g} / \mathrm{dL}^{8,25,28}$. However in AIDS patients with DMAC infection the anemia is profound and often occurs without similar decreases in white blood cell and platelet counts ${ }^{8,28}$. Our results, showing a significant difference between hemoglobin levels in cases and controls not explained only by advanced HIV infection, are in agreement with previously reported data.

Weight and Karnofsky score showed a progressive difference between cases and controls from the beginning of signs to diagnosis when most patients also had signs and symptoms or laboratory findings related to the gastrointestinal (GI) (e.g. abdominal pain, diarrhea, increased levels of alkaline phosphatase and $\gamma \mathrm{GT}$ ), or respiratory (cough, dyspnea, x-ray abnormalities) tracts.

HORSBURGH et al. ${ }^{16}$ showed findings referable to the GI tract or increased alkaline phosphatase in $76 \%$ of DMAC patients and a strong correlation between these findings and the presence of the disease. That study, however, was not controlled with a group of AIDS patients without DMAC. HAVLIK et al. ${ }^{12}$ also observed an association between elevated alkaline phosphatase (as well as fever, anemia, night sweats, weight loss and diarrhea) and DMAC. In their study, however, the AIDS patient control group was composed by considering the number of $\mathrm{CD}^{+}$cells (less than 100) as the sole criterion, and only 2 patients presented less than $50 \mathrm{CD}^{+}$cells (to characterize the advanced immunodeficiency).

In our cases we observed a high positivity of p24 Ag compared with controls. This finding accords with the concept of viral load in AIDS patients presenting opportunistic infections, what reflects HIV disease in progression.

Since we have not been able to observe any significant increase in the levels of alkaline phosphatase, as well as of $\gamma \mathrm{GT}$, related to the presence of DMAC in our study, it may be tempting to suggest that these laboratory abnormalities could be explained by overlap of other opportunistic diseases or even by complication of their treatment (usually for life), as immunosuppression advances in both groups.

A more recent prospective case/control study ${ }^{9}$ also showed abnormal titers of alkaline phosphatase in both cases and controls and high LDH levels only for cases, as reported in the present work. In that study, the authors also paired the controls using number of opportunistic diseases as one of the criteria. Like GORDIN et al. ${ }^{9}$, we consider that the association of increased LDH levels with DMAC, which had not been reported by others, could be the result of the high prevalence of respiratory signs or overlap of PCP in cases. In our study, however, statistical analysis could not support this hypothesis (Table 4). This finding suggest however that MAC bacteremia could play a role in the pathogenesis of $\mathrm{LDH}$ elevation.

Necropsy findings showed MAC in the lungs of $16 \%$ to $34 \%$ of DMAC patients ${ }^{2,14,29}$ but the importance of the lungs as a route for acquiring disseminated MAC infection is still controversial. Although some authors consider pulmonary presentation as a rare fact resulting from dissemination of the infection from other sites ${ }^{14,27}$, JACOBSON et al. ${ }^{18}$ reported a $33 \%$ sensitivity of positive respiratory cultures preceding the first positive culture from a sterile site by a median number of 25 days for predicting subsequent disseminated MAC. In the same way, CHIN et al. ${ }^{4}$ showed that $61 \%$ of patients presenting an induced sputum positive for MAC developed MAC bacteremia which appeared within a year, in $59 \%$ of the cases, and at most within the first 130 days. This more than twofold increase in the risk for MAC bacteremia allowed that group to conclude that the respiratory tract may correspond to a route of entry for MAC in HIV-infected patients.

In conclusion, in view of the data presented here and in previous paper, it seems that high levels of $\gamma \mathrm{GT}$ and alkaline phosphatase are laboratory findings associated with end-stages of AIDS and are not a result from DMAC infection. Conversely, high levels of LDH have been found associated with DMAC and not found in other advanced AIDS patients.

Although the incidence of DMAC infection and of other opportunistic diseases has fallen since protease inhibitors became largely used, resistance to antiretroviral therapy is now a reality that clinicians have to deal with. Therefore the unknown clinical evolution of AIDS patients hereafter, makes this and other studies on this subject reference to the management of DMAC infection in the future.

\section{RESUMO}

\section{Manifestações clínicas e laboratoriais da infecção disseminada pelo complexo Mycobacterium avium (DMAC) em um estudo caso/controle pareado}

Um estudo caso/controle pareado foi realizado no período compreendido entre janeiro de 1991 e junho de 1992, a fim de determinar a associação de manifestações clínicas e laboratoriais com a DMAC em pacientes com AIDS. Como a DMAC é habitualmente associada com imunodeficiência avançada e portanto também com outras doenças oportunistas, além do número de linfócitos $\mathrm{CD} 4^{+}$, casos e controles foram pareados utilizando-se os seguintes critérios: data do diagnóstico de AIDS e terapêutica anti-retroviral, número e gravidade das infecções oportunistas associadas e quando possível, tipo de profilaxia para Pneumocystis carinii, idade e sexo, nesta ordem de importância. Os casos (definidos como pacientes que apresentaram ao menos uma cultura positiva para MAC em sítio normalmente estéril) e controles apresentaram contagem de linfócitos $\mathrm{CD}^{+}$abaixo de 50/mm3. Uma prevalência significativamente alta de sinais gerais digestivos e respiratórios, elevação nos níveis de DHL, níveis baixos de hemoglobina e células $\mathrm{CD}^{+}$foi observada nos casos comparados aos controles. A elevação da $\gamma \mathrm{GT}$ e fosfatase alcalina observada nos casos foram também observadas nos controles. Em conclusão, a estratégia utilizada por nós para selecionar os controles nos permitiu detectar exames laboratoriais associados à 


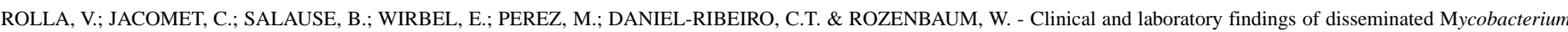
avium complex infection (DMAC) in a pair matched case-control study. Rev. Inst. Med. trop. S. Paulo, 41 (5): 273-277, 1999.

DMAC não observadas em outros pacientes com AIDS e imunossupressão avançada sem DMAC.

\section{REFERENCES}

1. BARRETO, J.A.; PALACI, M.; FERRAZOLI, L. et al. - Isolation of Mycobacterium avium complex from bone marrow aspirates of AIDS patients in Brazil. J. infect. Dis., 168: 777-779, 1993

2. BENSON, C.; KERNS, E.; SHA, B. et al. - Relationship of respiratory and GI tract colonization with Mycobacterium avium complex (MAC) to disseminate MAC disease in HIV-infected patients. In: INTERNATIONAL CONFERENCE ON AIDS, San Francisco, 1990. ABSTRACT Th B.514.

3. CDC - Centers for Disease Control and Prevention. Revision of the CDC surveillance case definition for acquired immunodeficiency syndrome. MMWR, 36: 1-158, 1987.

4. CHIN, D.P.; HOPEWELL, P.C.; YAJKO, D.M. et al. - Mycobacterium avium complex in the respiratory or gastrointestinal tract and the risk of $M$. avium complex bacteremia in patients with human immunodeficiency virus infection. J. infect. Dis., 169: 289$295,1994$.

5. CHIN, D.P.; REINGOLD, A.L.; STONE, E.N. et al. - The impact of Mycobacterium avium complex bacteremia and its treatment on survival of AIDS patients: a prospective study. J. infect. Dis., 170: 578-584, 1994.

6. DAUTZEMBERG, B.; CHAUVIN, J.; KOULAKSEZIAN, A. \& LACOEUR, H. - Les infections à Mycobacteries non tuberculeuses mises sous traitement expérimentaux en France. B.E.H, 44: 208-209, 1992.

7. EHMANN, W.; EYSTER, M.; WILSON, S. et al. - Relationship of CD4 lymphocyte counts to survival in a cohort of haemophiliacs infected with HIV. Multicenter Hemophilia Cohort Study. J. Acquir. Immune Defic. Syndr., 7: 1095-1098, 1994.

8. GARDENER, T.; FLANAGAN, P.; DRYDEN, M. et al. - Disseminated Mycobacterium avium intracellulare infection and red cell hypoplasia in patients with the acquired immunodeficiency syndrome. J. infect. Dis., 16: 135-140, 1988.

9. GORDIN, F.; COHN, D.; SULLAM, P. et al. - Early manifestations of disseminate Mycobacterium avium complex disease: a prospective evaluation. J. infect. Dis., 176: 126-132, 1997.

10. GRINSZTERJN, B.; FANDINHO, F.; VELOSO, V. et al. - Mycobacteremia in patients with the acquired immunodeficiency syndrome. Arch. intern. Med., 157: 23592363, 1997.

11. HADAD, D.; LEWI, D.; PIGNATARI, A. et al. - Resolution of Mycobacterium avium complex bacteremia following highly active antiretroviral therapy. Clin. infect. Dis., 26: $758-759,1998$

12. HAVLIK JR., J.A.; HORSBURGH JR., C.R.; METCHOCK, B. et al. - Disseminated Mycobacterium avium complex infection: clinical identification and epidemiologic trends. J. infect. Dis., 165: 577-580, 1992.

13. HAVLIR, D.V.; DUBE, M.P.; SATTLER, F.R. et al. - Prophylaxis against disseminated Mycobacterium avium complex with weekly azithromycin, daily rifabutin, or both California Collaborative Treatment Group. New Engl. J. Med., 335: 392-398, 1996.

14. HAWKINS, C.; GOLD, J.; WHIMBEY, E. et al. - Mycobacterium avium intracellulare infection in patients with the acquired immunodeficiency syndrome. Hum. Path., 18: $709-714,1986$.
15. HORSBURGH JR., C.R.; HAVLIK, J.A.; ELLIS, D.A. et al. - Survival of patients with acquired immune deficiency syndrome and disseminated Mycobacterium avium complex infection with and without antimycobacterial chemotherapy. Amer. Rev. resp. Dis., 144: 557-559, 1991.

16. HORSBURGH JR., C.R.; METCHOCK, B.; GORDON, S.M. et al. - Predictors of survival in patients with AIDS and disseminated Mycobacterium avium complex disease. J. infect. Dis., 170: 573-577, 1994.

17. JACOBSON, M.A. \& FRENCH, M. - Altered natural history of AIDS-related opportunistic infections in the era of potent combination antiretroviral therapy. Aids, 12: S157S163, 1998

18. JACOBSON, M.A.; HOPEWELL, P.C.; YAJKO, D.M. et al. - Natural history of disseminated Mycobacterium avium complex infection in AIDS. J. infect. Dis., 164 994-998, 1991.

19. KRAVCIK, S.; TOYE, B.W.; FYKE, K. et al. - Impact of Mycobacterium avium complex prophylaxis on the incidence of mycobacterial infections and transfusion-requiring anemia in an HIV-positive population. J. Acquir. Immune Defic. Syndr. Hum. Retrovirol., 13: 27-32, 1996.

20. LASSEUR, C.; MAUGEIN, J.; PELLEGRIN, J.L. et al. - Disseminated Mycobacterium avium complex infections in AIDS. A propose of 100 cases. [Groupe d'Epidemiologie clinique du SIDA en Aquitaine]. Rev. Med. interne, 16: 110-120, 1995

21. MERTL, S.L. - The role of clarithromycin in the prophylaxis of disseminated Mycobacterium avium-intracellulare infection in patients with AIDS. Pharmacotherapy, 16: 393-400, 1996.

22. MUSIAL, C.; TICE, L.; STOCKMANN, L. \& ROBERTS, G. - Identification of mycobacteria from culture by using the Gen-Probe rapid diagnostic system for Mycobacterium avium complex and Mycobacterium tuberculosis complex. J. clin. Microbiol., 26: 2120-2123, 1988.

23. NIGHTINGALE, S.D.; BYRD, L.T.; SOUTHERN, P.M. et al. - Incidence of Mycobacterium avium-intracellulare complex bacteremia in human immunodeficiency virus-positive patients. J. infect. Dis., 165: 1082-1085, 1992.

24. NORÜIS, M. - Statistical program for social science. 7.ed. Chicago, SPSS, 1995.

25. PERKOCHA, L. \& RODGER, G. - Hematologic aspects of human immunodeficiency virus infection: laboratory and clinical considerations. Amer. J. Hemat., 29: 94-105, 1994

26. PIERCE, M.; CRAMPTON, S.; HENRY, D. et al. - A randomized trial of clarithromycin as prophylaxis against disseminated Mycobacterium avium complex infection in patients with advanced acquired immunodeficiency syndrome. New Engl. J. Med., 335: $384-391,1996$.

27. RUF, B.; SHUERMANN, D.; BREHMER, W. \& POHLE, H. - Pulmonary manifestation due to Mycobacterium avium-intracellulare in AIDS patients. Amer. Rev. resp. Dis., (suppl.): A611, 1990.

28. TREACY, M.; COSTELLO, C. \& CLARK, A. - Peripheral blood and bone marrow abnormalities in patients with HIV related disease. Brit. J. Haemat., 65: 289-294, 1987.

29. WALLACE, J.M. \& HANNAH, J.B. - Mycobacterium avium complex infection in patients with the acquired immunodeficiency syndrome. A clinicopathologic study. Chest 93: 926-932, 1988.

Received: 19 January, 1999

Accepted: 31 August, 1999 